\title{
Cost-Effective Membrane and Advanced Electrode for Stable Polysulfide-Ferricyanide Flow Battery
}

\author{
Xuechun Lou, ${ }^{1}$ Hu Fu, ${ }^{1}$ Jian Xu, ${ }^{1}$ Yong Long, ${ }^{1}$ Su Yan, ${ }^{1}$ Haitao Zou, ${ }^{1}$ Bo Lu, ${ }^{1}$ Murong He, \\ Mei Ding $\mathbb{D}^{1,2}$ Xiaobo Zhu $\mathbb{D}^{1},{ }^{1}$ and Chuankun Jia $\mathbb{D}^{1,2}$ \\ ${ }^{1}$ College of Materials Science and Engineering, Changsha University of Science \& Technology, Changsha 410114, China \\ ${ }^{2}$ National Engineering Laboratory of Highway Maintenance Technology, School of Traffic \& Transportation Engineering, \\ Changsha University of Science \& Technology, Changsha 410114, China
}

Correspondence should be addressed to Mei Ding; dingmei@csust.edu.cn, Xiaobo Zhu; xbzhu@outlook.com, and Chuankun Jia; jiachuankun@csust.edu.cn

Received 31 August 2021; Accepted 31 December 2021; Published 29 January 2022

Copyright (c) 2022 Xuechun Lou et al. Exclusive Licensee Beijing Institute of Technology Press. Distributed under a Creative Commons Attribution License (CC BY 4.0).

Based on inexpensive, safe, and environmentally friendly active redox species, neutral polysulfide-ferrocyanide redox flow batteries (PFRFBs) have attracted much attention for large-scale energy storage. However, the development of PFRFBs is undermined by the expensive commercial membrane materials as well as the sluggish polysulfide redox reactions. This work attempts to solve these critical problems by combining the economical membrane with the highly catalytic electrode. In specific, $\mathrm{K}^{+}$-exchanged sulfonated polyether ether ketone (SPEEK-K) membranes have been investigated in PFRFBs to replace the costly Nafion membrane. SPEEK-K with optimized degree of sulfonation enables the PFRFB high average coulombic efficiency of $99.80 \%$ and superior energy efficiency of $90.42 \%$ at a current density of $20 \mathrm{~mA} \mathrm{~cm}^{-2}$. Meanwhile, to overcome the kinetic limitations of polysulfide redox reactions, a CuS-modified carbon felt electrode is demonstrated with excellent catalytic performance, enabling the PFRFB higher and more stable energy efficiency over cycling. The combination of the cost-effective membrane with the catalytic electrode in one cell leads to a capacity retention of $99.54 \%$ after 1180 cycles and an outstanding power density (up to $223 \mathrm{~mW} \mathrm{~cm}^{-2}$ ). The significant enhancements of electrochemical performance at reduced capital cost will make the PFRFB more promising for large-scale energy storage systems.

\section{Introduction}

The increasing severity of climate change is pushing a global energy transition from fossil fuels to renewable energy sources such as solar and wind. Due to the intermittent nature of these renewables, energy storage technologies play a critical role in integrating them into the grid. To facilitate the energy transition, the energy storage technologies are required to be efficient, safe, and affordable [1-3]. Owing to merits of design flexibility, deep-discharge capability, high efficiency, long cycle life, etc., redox flow batteries (RFBs) stand as attractive candidates for sizeable energy storage [4-6]. Currently, all-vanadium RFBs represent the most successful ones, which have been successfully demonstrated from the 1980s [7-9]. However, the high cost of the vanadium, low energy density $(25 \mathrm{Wh} / \mathrm{L})$, and strong acidity of the electrolytes hinder the widespread deployment of all- vanadium RFBs. Recently, organic RFBs based on organic redox-active species instead of metal elementals from mineral resources can potentially reduce the capital cost $[10$, 11]. However, the design of redox-active organic materials with desirable electrochemical performances remains challenging [12]. To this end, many efforts have been directed to the investigations of new RFBs to achieve low cost [13-15], high energy density [16-19], low capacitance decay rate [20-22], and long lifetime [23-29].

Among emerging RFBs, neutral polysulfide-ferricyanide RFBs (PFRFBs) have attracted much attention because both the redox species of ferri/ferrocyanide and polysulfide are made from abundant, inexpensive, and environmentally benign raw materials [30]. In fact, the ferri/ferrocyanide couple features well-defined redox behaviors and fast electron transfer kinetics [31] that has been extensively used in pairing with other electrochemically active reactants, such as 


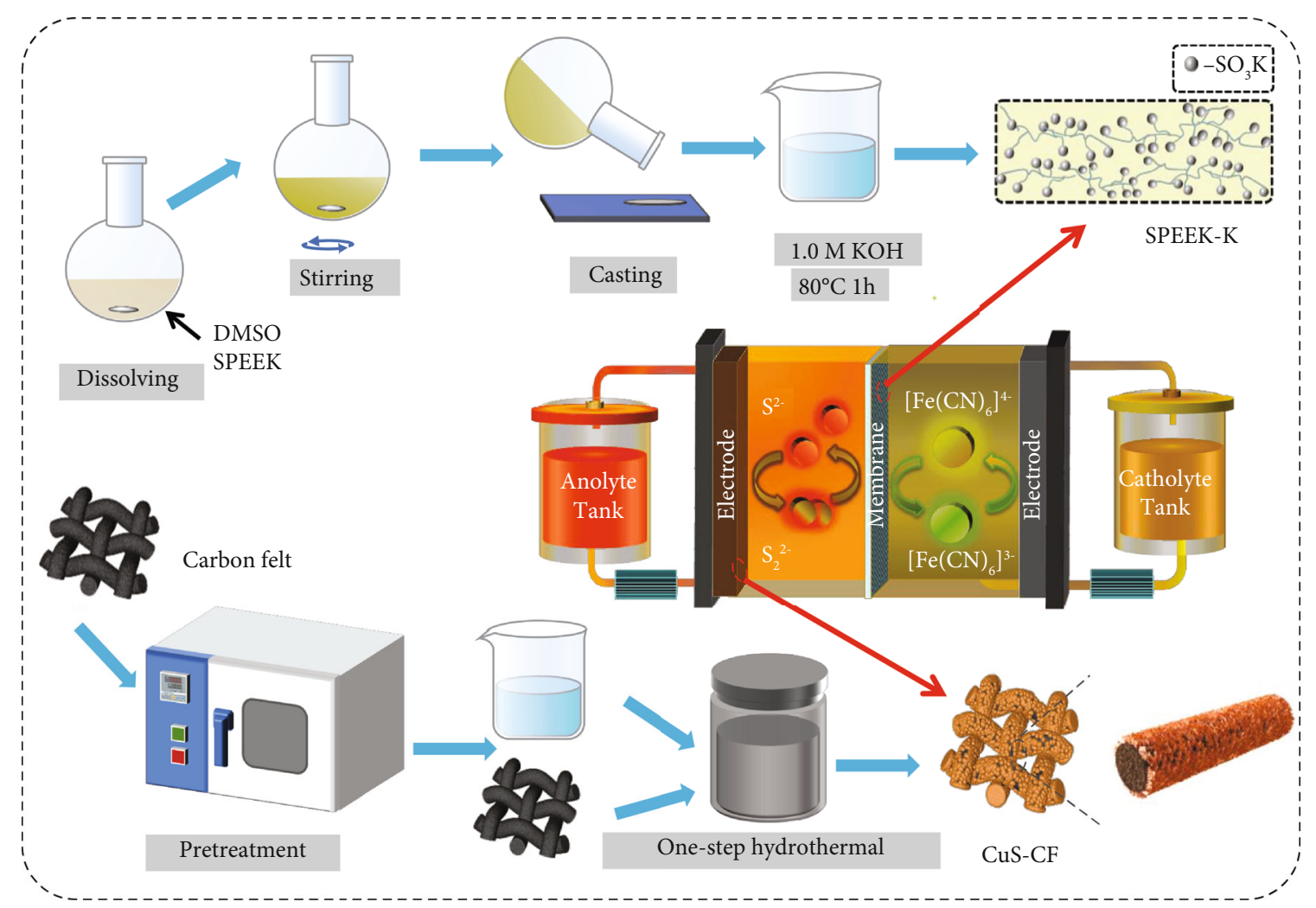

FIGURE 1: Schematic illustration of key material design processes for a cost-effective and high-performance PFRFB cell.

quinone, anthraquinone, and benzoquinone-based anolytes [32-35]. On the other hand, the polysulfide that originated from cheap and abundant sulfur is also a promising redoxactive material, which has been demonstrated for lithiumsulfur batteries [36-38] and polysulfide redox flow batteries [39-41]. In our previous work, a PFRFB was demonstrated using high concentrated ferricyanide and polysulfide as reactants, leading to a further improvement of the energy density. And the chemical cost of PFRFBs can achieve only $32.47 \$ / \mathrm{kWh}$ when considering the expenses on redox and supporting materials [42]. However, the polysulfide redox reactions, which are well known for the slow reaction kinetics, possess difficulties to match with the ferri/ferrocyanide cathodic side, resulting in unfavorable cell performance. Besides, although the redox materials in PFRFB system are inexpensive, the significant cost of around $800.00 \$ / \mathrm{m}^{2}$ [4] for commercial Nafion membrane is still hindering its market penetration [43].

Herein, we aim to address the two critical problems in PFRFBs by combining membrane and electrode optimizations. First, to replace the costly Nafion membrane, lowcost sulfonated polyether ether ketone (SPEEK) membranes (approximately $21.89 \quad \$ / \mathrm{m}^{2}$ ) [44-46] have been $\mathrm{K}^{+}$exchanged for use in PFRFBs. By controlling the degree of sulfonation (DS), the $\mathrm{K}^{+}$-exchanged SPEEK (SPEEK-K) membrane shows balanced conductivity and ferricyanide permeability. Second, taking advantage of the catalytic effects of metal sulfides toward the polysulfide redox reactions [47-49], carbon felt (CF) deposited with CuS nanosheets (CuS-CF) has been investigated as the anodic electrode, which exhibits excellent charge transfer and catalytic properties for polysulfide redox reactions. The combination of the cost-effective membrane with the catalytic electrode in the PFRFB leads to excellent capacity retention of $99.54 \%$ as well as an outstanding power density. The scheme of the membrane and electrode designs is presented in Figure 1.

\section{Materials and Methods}

2.1. Materials. Polyether ether ketone (PEEK, 450PF) was purchased from Victrex. Sulfuric acid $\left(\mathrm{H}_{2} \mathrm{SO}_{4}, 98 \mathrm{wt} . \%\right)$, dimethyl sulfoxide (DMSO), potassium ferricyanide $\left(\mathrm{K}_{3}\left[\mathrm{Fe}(\mathrm{CN})_{6}\right]\right)$, potassium polysulfide $\left(\mathrm{K}_{2} \mathrm{~S}_{x}, \geq 40 \% \mathrm{~K}_{2} \mathrm{~S}\right.$ basis, $x$ was determined as 2 ), potassium chloride $(\mathrm{KCl})$, copper sulfate pentahydrate $\left(\mathrm{CuSO}_{4} \cdot 5 \mathrm{H}_{2} \mathrm{O}\right)$, and thiourea $\left(\mathrm{CH}_{4} \mathrm{~N}_{2} \mathrm{~S}\right)$ were ordered from Sinopharm Chemical Reagent Co. Ltd. All of them were used as received without any treatment. Nafion 212 membrane (N212) was supplied by Ion Power Inc., USA.

2.2. Preparation of SPEEK-K and N212-K Membranes. According to our previous work [44, 45], the DS of SPEEK was controlled to be about $47.0 \%, 57.0 \%$, and $67.0 \%$, respectively, which were measured by the titration method [50]. For the preparation of SPEEK membranes, $1.60 \mathrm{~g}$ SPEEK was dissolved in $50.0 \mathrm{~mL}$ dimethyl sulfoxide (DMSO) under stirring at $80^{\circ} \mathrm{C}$. The resulted solution was cast onto a homemade glass plate and dried in the oven at $100^{\circ} \mathrm{C}$ for overnight. After cooling down, the membrane was peeled off. 
The as-prepared SPEEK membrane and purchased N212 were pretreated before use. Prior to use, the membranes were heated in $1.0 \mathrm{M} \mathrm{KOH}$ solution at $80^{\circ} \mathrm{C}$ for $1 \mathrm{~h}$ followed by washing away residual $\mathrm{KOH}$ with deionized water at room temperature. The resulting $\mathrm{K}^{+}$-exchanged membrane was soaked in deionized water and ready to use. Based on the different DS of SPEEK, the membranes were named DS47-K, DS57-K, and DS67-K, respectively. The commercial N212 was treated following the same procedures and named $\mathrm{N} 212-\mathrm{K}$ as the reference.

2.3. Preparation of $\mathrm{CuS}-\mathrm{CF}$ Electrode. The CuS-CF electrode was prepared according to a typical and one-step hydrothermal procedure. Prior to the deposition of $\mathrm{CuS}$, CF was heated at $400^{\circ} \mathrm{C}$ for $12 \mathrm{~h}$ under air atmosphere to improve its wettability. Then, $0.61 \mathrm{~g} \mathrm{CuSO}_{4} \cdot 5 \mathrm{H}_{2} \mathrm{O}$ and $3.05 \mathrm{~g} \mathrm{CH}_{4} \mathrm{~N}_{2} \mathrm{~S}$ were dissolved in $50.0 \mathrm{~mL}$ deionized water. After stirring for over $30 \mathrm{~min}$, the resulted solution was transferred into a $100.0 \mathrm{~mL}$ Teflon-lined autoclave. Subsequently, a piece of heat-treated CF $\left(3.0 \times 4.5 \mathrm{~cm}^{2}\right)$ was soaked in the solution. Then, the reactor was kept at $180^{\circ} \mathrm{C}$ for $4 \mathrm{~h}$ in an oven. Finally, the CuS-CF was collected, washed with deionized water, and dried at $80^{\circ} \mathrm{C}$ for $10 \mathrm{~h}$ before use.

2.4. Membrane Characterizations. A scanning electron microscope (SEM, Zeiss EVO 10) equipped with an energy-dispersive spectrometer (EDS) was used to detect the morphologies and element distributions of membranes. The surface morphologies of N212, SPEEK, N212-K, and SPEEK-K membranes were obtained by an atomic force microscope (AFM, Bruker Nano Inc. Dimension Icon). Other physicochemical properties were recorded according to reported methods, and details were presented as follows.

2.4.1. Ion Exchange Capacity (IEC). IEC and DS were measured by typical chemical titration methods according to earlier studies $[46,51]$. The membrane was soaked in a saturated $\mathrm{NaCl}$ solution for $48 \mathrm{~h}$ to ensure that all $\mathrm{H}^{+}$of the membrane were liberated into the solution. After that, the solution was titrated with $0.01 \mathrm{M} \mathrm{NaOH}$ solution. IEC was calculated by the following:

$$
\mathrm{IEC}=\frac{C_{\mathrm{NaOH}} \times V_{\mathrm{NaOH}}}{W_{\mathrm{dry}}} .
$$

$C_{\mathrm{NaOH}}$ and $V_{\mathrm{NaOH}}$ are the concentration and consumed volume of $\mathrm{NaOH}$ solution, respectively. $W_{\text {dry }}$ represents the weight of dry membrane.

2.4.2. Swelling Ratio (SR). By testing the length of wet and dry membrane, respectively, SR of membranes were calculated by Equation (2). Note that wet membranes refer to the membranes which were soaked in deionized water at room temperature for $48 \mathrm{~h}$. All of them were dried in an oven at $80^{\circ} \mathrm{C}$ for overnight before measuring the length of dry membranes.

$$
\mathrm{SR}=\frac{L_{\mathrm{w}}-L_{\mathrm{d}}}{L_{d}} \times 100 \% .
$$

$L_{\mathrm{w}}$ and $L_{\mathrm{d}}$ are the length of wet membrane and dry membrane, respectively.

2.4.3. Area Resistance (AR) and Conductivity $(\sigma)$. The AR of membranes was measured by a resistance tester (DME-20, China) after the cell was circulated for $5 \mathrm{~min}$ in which the positive and negative reservoirs were both filled with $20.0 \mathrm{~mL}$ solution of $2.0 \mathrm{M} \mathrm{KCl}$. The conductivity $(\sigma)$ of membranes was obtained according to

$$
\sigma=\frac{T}{S\left(R_{2}-R_{1}\right)} .
$$

$T$ and $S$ refer to the thickness and working area $\left(13.5 \mathrm{~cm}^{2}\right)$ of the membrane, respectively. $R_{2}$ and $R_{1}$ are the cell's resistance with and without the membrane, respectively.

2.4.4. Ion Permeability and Ion Selectivity. To verify the electrochemical active ion permeation through membranes, the $\mathrm{H}$-shaped device separated by a piece of membrane (Figure S1) was utilized to measure the permeability of $\left[\mathrm{Fe}(\mathrm{CN})_{6}\right]^{3-}$. The left compartment was filled with $0.1 \mathrm{M}$ $\mathrm{K}_{3}\left[\mathrm{Fe}(\mathrm{CN})_{6}\right]$ in $1.0 \mathrm{M} \mathrm{KCl}$, and the right compartment was filled with $0.1 \mathrm{M} \mathrm{CaCl} 2$ in $1.0 \mathrm{M} \mathrm{KCl}$. A UV-vis spectrometer (TU-1900) was used to monitor the concentration variations of $\left[\mathrm{Fe}(\mathrm{CN})_{6}\right]^{3-}$. Samples were taken out from the $\mathrm{CaCl}_{2}$ compartment at an interval of $12 \mathrm{~h}$. After each measurement, the sample was poured back into the same reservoir to keep the solution volume invariant. The ion selectivity is defined as the ratio of the $\mathrm{K}^{+}$conductivity to the permeability of $\left[\mathrm{Fe}(\mathrm{CN})_{6}\right]^{3-}$ ions through membranes.

2.5. Electrode Characterizations. The surface morphologies of the electrode were observed by SEM (Zeiss EVO 10). The cyclic voltammetry $(\mathrm{CV})$ tests were performed using a three-electrode cell configuration with carbon felt $(1.0 \mathrm{~cm} \times 1.0 \mathrm{~cm})$ as the working electrode, a platinum mesh as the counter electrode, and an $\mathrm{Ag} / \mathrm{AgCl}(3.0 \mathrm{M} \mathrm{KCl})$ reference electrode as the reference electrode at a VSP BioLogic workstation. The electrochemical impedance spectroscopy (EIS) tests were conducted with the same device with frequencies ranging from $10 \mathrm{MHz}$ to $100 \mathrm{kHz}$ at an amplitude of $15 \mathrm{mV}$.

2.6. Cell Tests. PFRFB cells were assembled by sandwiching the different membranes between CuS-CF anode and pristine CF cathode. Graphite plate and copper foil served as the current collector. The active area of the working electrode was $13.5 \mathrm{~cm}^{2}$. Potassium ferricyanide and potassium polysulfide were used as positive and negative active materials, respectively. Galvanostatic cycling performance was conducted on Neware battery testing systems at room temperature. The open-circuit voltage decay (OCV) and rate performance from 20 to $140 \mathrm{~mA} \mathrm{~cm}^{-2}$ at an interval of $20 \mathrm{~mA} \mathrm{~cm}^{-2}$ was measured by Arbin battery testing system (BT-I, Arbin, USA). Polarization curves were obtained by employing an optimized cell (electrode area was $4.0 \mathrm{~cm}^{2}$ ) at $100 \%$ state of charge (SOC) from the Arbin instrument 


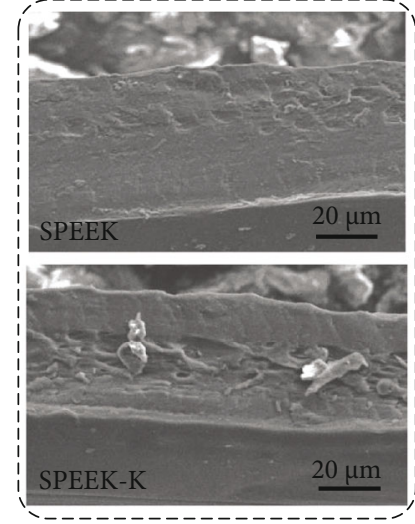

(a)
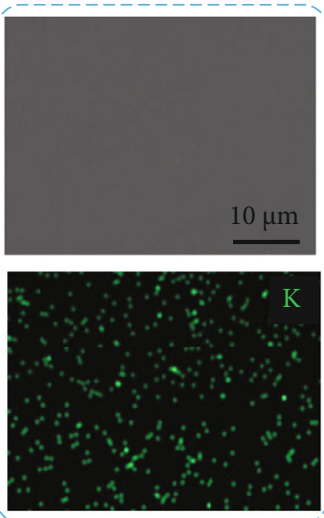

(b)

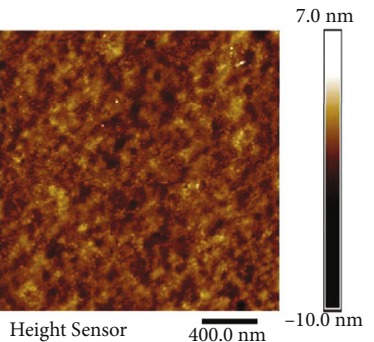

(e)

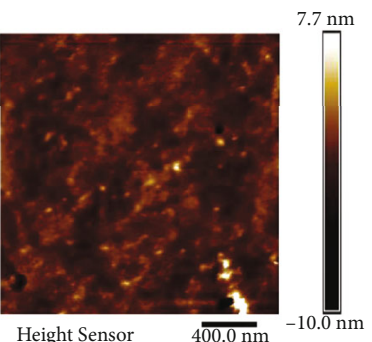

(f)

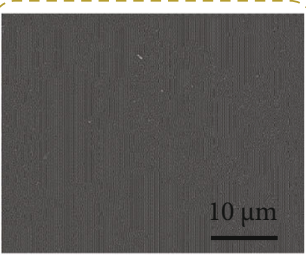

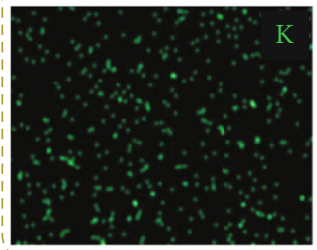

(c)

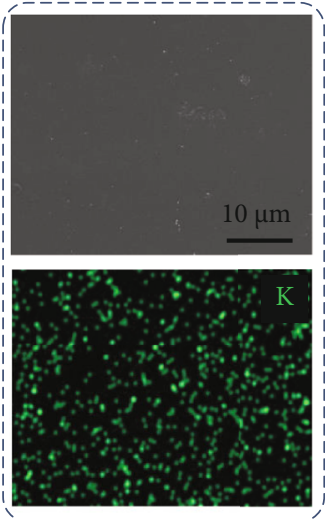

(d)

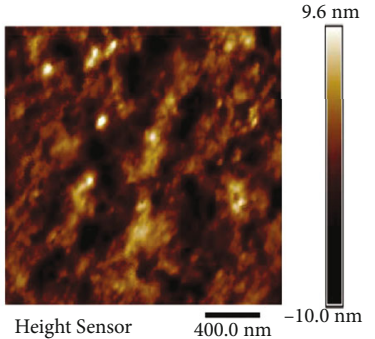

(g)

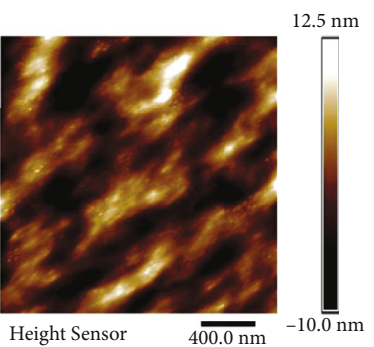

(h)

FIgURE 2: (a) The SEM images of the cross-sectional morphologies of SPEEK and SPEEK-K (DS57-K). The SEM surface images and corresponding EDS mapping results of (b) DS47-K, (c) DS57-K, and (d) DS67-K. The AFM images of (e) SPEEK, (f) DS47-K, (g) DS57-K, and (h) DS67-K.

TABLE 1: Thickness, IEC, SR, AR, and $\mathrm{K}^{+}$conductivity values of SPEEK-K membranes in comparison with N212-K.

\begin{tabular}{|c|c|c|c|c|c|}
\hline Membranes & Thickness $(\mu \mathrm{m})$ & IEC $\left(\mathrm{mmol} \mathrm{g}^{-1}\right)$ & SR (\%) & $\operatorname{AR}\left(\Omega \mathrm{cm}^{2}\right)$ & Conductivity $\left(\mathrm{mS} \mathrm{cm}^{-1}\right)$ \\
\hline N212-K & 50.00 & 0.86 & 3.72 & 1.59 & 16.84 \\
\hline DS47-K & $65 \pm 3.00$ & 1.27 & 3.81 & 0.80 & 17.16 \\
\hline DS57-K & $65 \pm 3.00$ & 1.45 & 4.62 & 0.74 & 19.08 \\
\hline DS67-K & $65 \pm 3.00$ & 1.84 & 4.85 & 0.71 & 22.89 \\
\hline
\end{tabular}

(BT-I) with the current being gradually increased by $10 \mathrm{~mA}$ per second from $260 \mathrm{~mA}$.

Catholyte with three different concentrations $(0.1 \mathrm{M}$, $0.5 \mathrm{M}$, and $\left.0.8 \mathrm{M} \mathrm{K}_{3}\left[\mathrm{Fe}(\mathrm{CN})_{6}\right]\right)$ and anolyte with $2.0 \mathrm{M} \mathrm{K}_{2} \mathrm{~S}$ were obtained by dissolving $\mathrm{K}_{3}\left[\mathrm{Fe}(\mathrm{CN})_{6}\right]$ and $\mathrm{K}_{2} \mathrm{~S}$ in $1.0 \mathrm{M}$ $\mathrm{KCl}$ solution, respectively. The cell employed a $25.0 \mathrm{~mL}$ solution of $\mathrm{K}_{3}\left[\mathrm{Fe}(\mathrm{CN})_{6}\right]$ in $1.0 \mathrm{M} \mathrm{KCl}$ as catholyte and a $15.0 \mathrm{~mL}$ solution of $2.0 \mathrm{M} \mathrm{K}_{2} \mathrm{~S}$ in $1.0 \mathrm{M} \mathrm{KCl}$ as anolyte for cell performance tests, unless otherwise specialized. Both catholyte and anolyte were pumped between the storing tank and the corresponding compartment of the electrochemical cell by a peristaltic pump (Williamson Manufacturing Co., Ltd., UK).

\section{Results}

\subsection{SPEEK-K Membranes for PFRFBs}

3.1.1. Morphologies of Membranes. After the $\mathrm{K}^{+}$exchange, the cross-sectional morphology of SPEEK-K (DS57-K) becomes rougher with respect to that of SPEEK (Figure 2(a)). Besides, the surface morphologies of SPEEK-
$\mathrm{K}$ membranes are rough, too (Figures 2(b)-2(d)). The same trend is observed for $\mathrm{N} 212-\mathrm{K}$ compared to N212 (Figures S2a and S2c). From DS47-K and DS57-K to DS67-K, more and more $\mathrm{K}^{+}$ions are present which are in direct proportion to the amounts of $\mathrm{H}^{+}$from the sulfonic acid groups. Moreover, the homogeneous distributions of $\mathrm{K}^{+}$ions into the matrixes are verified by the EDS mapping results (Figures 2(b)-2(d)). To evaluate the influences of $\mathrm{K}^{+}$on properties of membranes, AFM images have been recorded. Compared with N212 (Figure S2b) and SPEEK (Figure 2(e)) membranes, N212-K (Figure S2d) and SPEEK-K membranes (Figures 2(f)-2(h)) display more apparent dark regions. In particular, along with the increase of DS, from DS47-K and DS57-K to DS67-K, the dark regions from the AFM images gradually become bigger. These results suggest that $\mathrm{K}^{+}$ions modify the water channels of the membranes and then increase the hydrophilicity.

3.1.2. Physiochemical Properties of Membranes. The thickness, IEC, SR, AR, and $\mathrm{K}^{+}$conductivity values of the membranes have been measured and compared in Table 1. As 


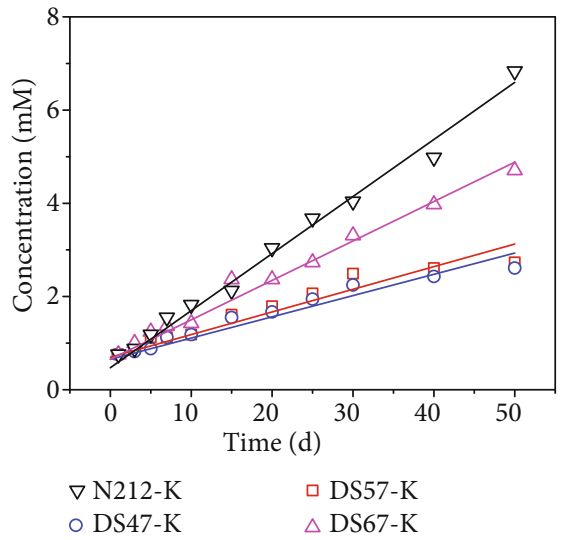

(a)

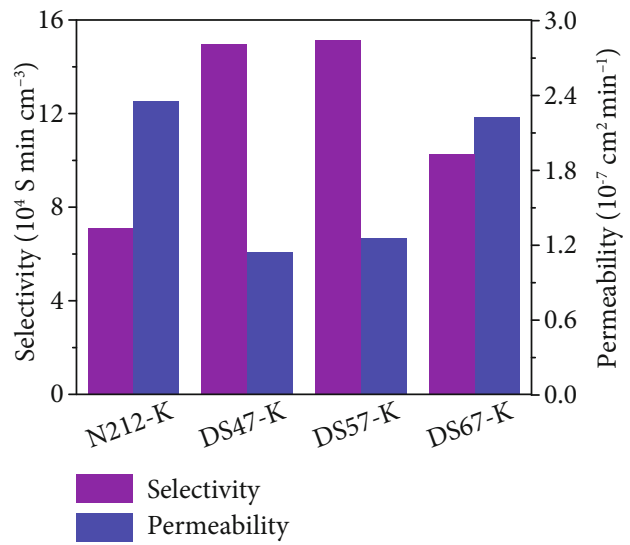

(b)

FIgURE 3: (a) The changes of $\left[\mathrm{Fe}(\mathrm{CN})_{6}\right]^{3-}$ concentration in the blank reservoirs separated by different membranes. (b) Comparisons of the permeability and the ion selectivity of these membranes.

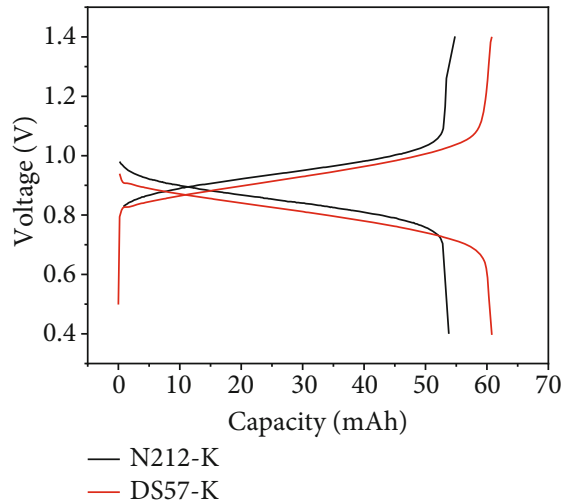

(a)

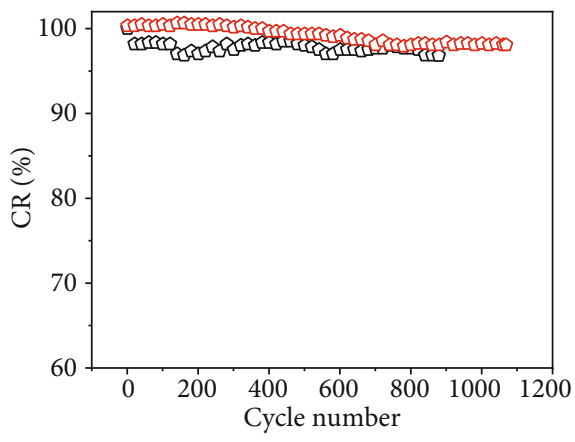

$\checkmark \mathrm{N} 212-\mathrm{K}$

$\checkmark$ DS57-K

(c)

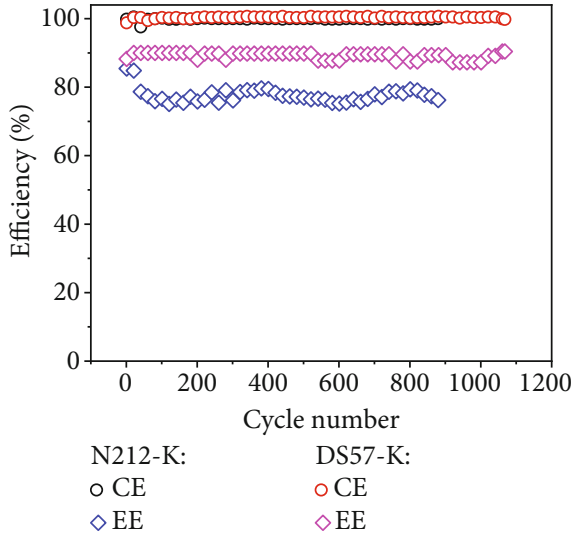

(b)

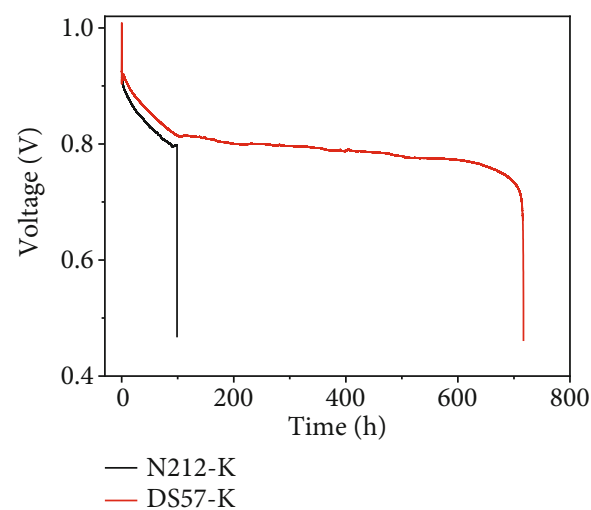

(d)

FIGURE 4: Electrochemical performance of PFRFB cells with N212-K and DS57-K membrane, respectively. (a) Charge/discharge curves of the first cycle. (b) CE and EE. (c) CR. For (a-c) cycling tests, the applied current density is $20 \mathrm{~mA} \mathrm{~cm}^{-2}$. (d) Curves of self-discharge behaviors.

anticipated, SPEEK-K membranes show higher IEC and SR values compared to $\mathrm{N} 212-\mathrm{K}$ due to the involvement of hydrophilic sulfonic acid groups. Moreover, the IEC and $\mathrm{SR}$ values of SPEEK-K membranes improve from 1.27 to 1.84 and from $3.81 \%$ to $4.85 \%$, respectively, along with the increase of DS. Such results further confirm the role of sul- fonic acid groups in boosting the absorption and the retention of water molecules within the membranes. Generally, high SR values benefit ion conductivity [42]. As a result, the AR value is reduced from $1.59 \Omega \mathrm{cm}^{2}$ for $\mathrm{N} 212-\mathrm{K}$ to $0.80,0.74$, and $0.71 \Omega \mathrm{cm}^{2}$ for DS47-K, DS57-K, and DS67-K, respectively. Correspondingly, the $\mathrm{K}^{+}$conductivity 


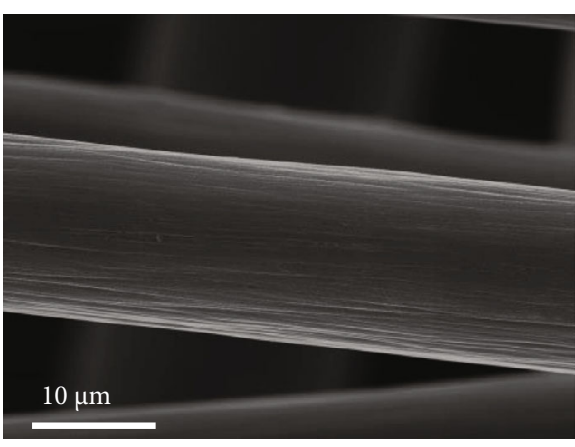

(a)

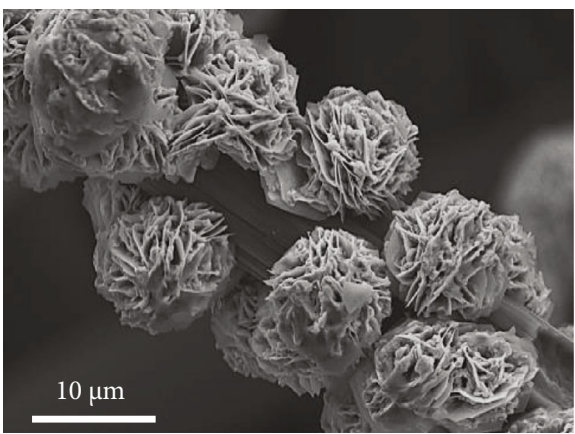

(c)

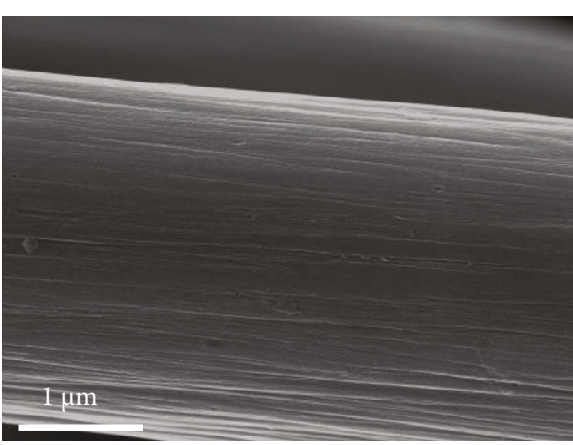

(b)

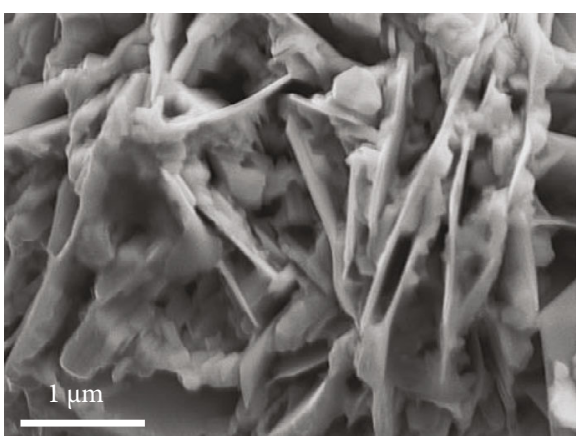

(d)

FIgURE 5: SEM images of $(a, b)$ pristine CF and (c, d) CuS-CF under different magnifications.

of the membranes increases from $16.84 \mathrm{mS} \mathrm{cm}^{-1}$ for $\mathrm{N} 212-\mathrm{K}$ to $17.16,19.08$, and 22.89 for DS47-K, DS57-K, and DS67-K, respectively.

Figure 3(a) shows the variations of $\left[\mathrm{Fe}(\mathrm{CN})_{6}\right]^{3-}$ concentration in the blank reservoirs, which reveal the permeability of membranes. The permeation rate of SPEEK-K membranes increases with the increase of DS, as high DS means more $-\mathrm{SO}_{3} \mathrm{H}$ groups in the polymer matrix, which effectively improves the $\mathrm{K}^{+}$conductivity (Table 1 ) and accelerates the crossover of active species through the membranes. Nevertheless, all the SPEEK-K membranes exhibit lower permeability of active species compared with N212-K. According to Figure 3(b), the permeation rate of membranes is reduced from $2.23 \times 10^{-7} \mathrm{~cm}^{2} \mathrm{~min}^{-1}$ for the $\mathrm{N} 212-\mathrm{K}$ to $2.37 \times 10^{-7}$ $\mathrm{cm}^{2} \mathrm{~min}^{-1}$ for the highly sulfonated DS67-K, which is further decreased to $1.26 \times 10^{-7} \mathrm{~cm}^{2} \mathrm{~min}^{-1}$ and $1.15 \times 10^{-7} \mathrm{c}$ $\mathrm{m}^{2} \mathrm{~min}^{-1}$ for DS57-K and DS47-K, respectively. Ion selectivity, which is defined as the ratio of the conductivity and the permeability, is normally used to reflect the overall performance of the membranes. As disclosed in Figure 3(b), all the SPEEK-K membranes demonstrate considerably higher ion selectivity values over N212-K. Among them, DS57-K shows the highest ion selectivity of $15.15 \times 10^{4} \mathrm{~S}$ min $\mathrm{cm}^{-3}$, attributing to the suppressed ferricyanide permeation as well as the enhanced $\mathrm{K}^{+}$conductivity.

3.1.3. Effects of Membranes on Cell Performance. To study the effects of the membranes on PFRFB cell performance and figure out the optimized membrane, N212-K and a series of SPEEK-K membranes with different DS have been continuously cycled in PFRFB cells at a current density of $20 \mathrm{~mA} \mathrm{~cm}^{-2}$. All these cells show the high coulombic effi- ciency (CE) (Figure S3a). It is noted that the cell with DS57-K membrane delivers an average energy efficiency (EE) of $90.42 \%$ and remains stable over 1051 cycles, while the EE of the cells with other membranes declines rapidly after 250 cycles due to the gradually increasing polarization of the cells (Figure S3b). Besides, compared with other membranes, the cell with DS57-K membrane demonstrates the highest discharge capacity retention (CR) after 1051 cycles (Figure S3c). In line with the cycling tests, PFRFBs using SPEEK-K membranes survive longer during the tests of open-circuit voltage decay with respect to that of the cell with N212-K (Figure S4). In particular, the cell with DS57$\mathrm{K}$ shows the minimum self-discharge behavior, in good agreement with the highest ion selectivity of DS57-K.

Figure 4(a) shows the charge/discharge profiles of the cells with DS57-K and N212-K membrane, respectively. The cell using DS57-K exhibits a higher discharge capacity (60.8 mAh) than $\mathrm{N} 212-\mathrm{K}$-based cell $(53.8 \mathrm{mAh})$, which is in good agreement with the lower ion permeability and higher ion selectivity of DS57-K membrane. The cells which, respectively, employ $\mathrm{N} 212-\mathrm{K}$ and DS57-K membrane both exhibit high CE of around $99.80 \%$ over 1051 cycles. However, the EE of DS57-K-based cell is much higher and more stable than that of N212-based counterpart. The cell with DS57-K membrane enables a stable EE of $90.42 \%$ for 1051 cycles. When $\mathrm{N} 212-\mathrm{K}$ membrane is used, the EE is only $77.82 \%$ after 879 cycles (Figure 4(b)). Besides, the DS57-Kbased cell shows the higher CR than N212-K-based cell (Figure 4(c)). In addition, as shown in Figure 4(d), the use of DS57-K membrane dramatically prolongs the selfdischarge duration time of the PFRFB. The DS57-K-based PFRFB cell maintains about 717 hours, which is sixfold 


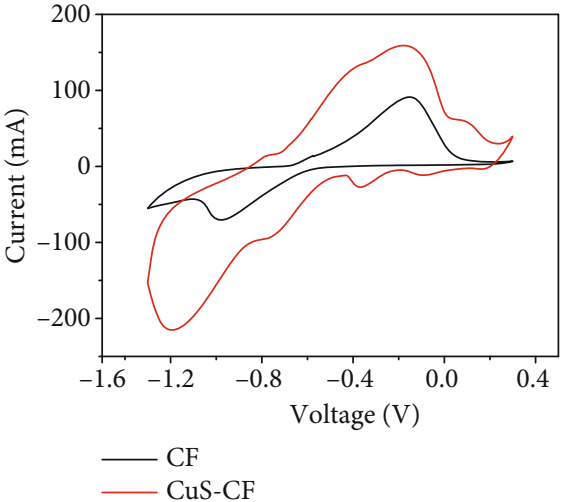

(a)

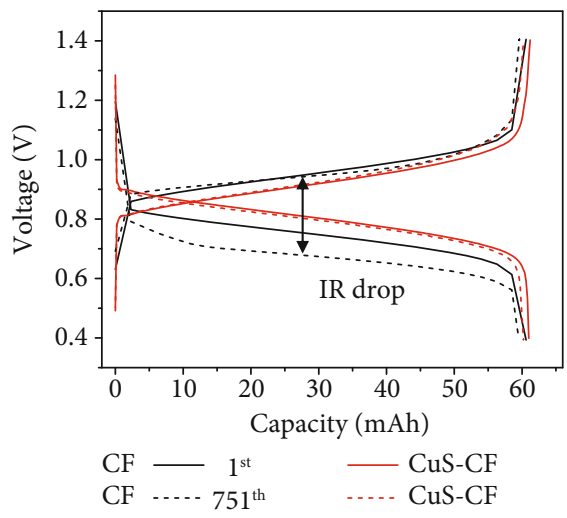

(c)

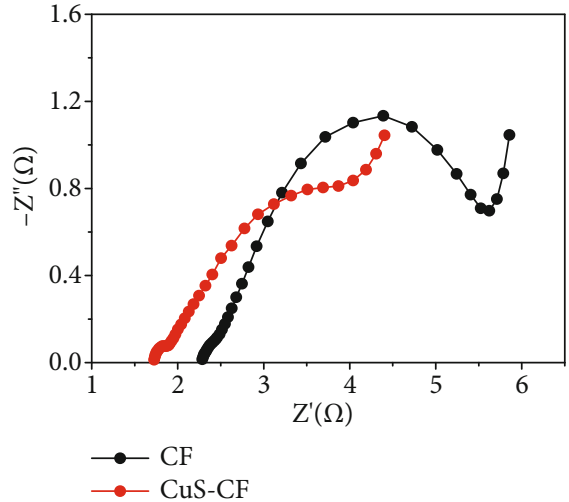

(b)

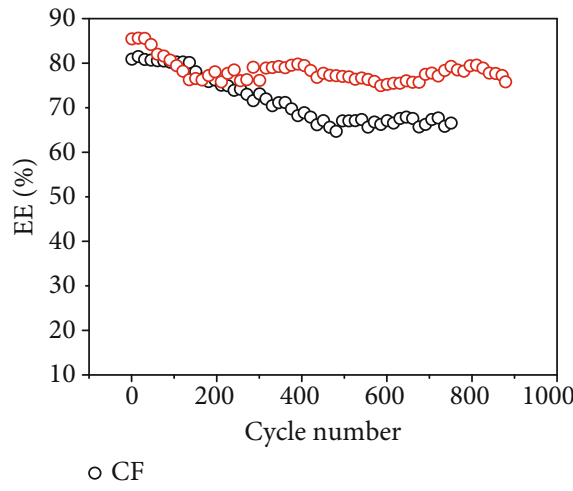

(d)

Figure 6: (a) CV curves on pristine $\mathrm{CF}$ and $\mathrm{CuS}-\mathrm{CF}$ at a scanning rate of $10 \mathrm{mV} \mathrm{s}^{-1}$, respectively. (b) Nyquist plots of the pristine $\mathrm{CF}$ and the CuS-CF, respectively. (c) Selected charge/discharge curves of PFRFB cells with different electrodes. (d) EE values of PFRFB cells with CF and CuS-CF electrodes at $20 \mathrm{~mA} \mathrm{~cm}^{-2}$, respectively.

longer than that of N212-K-based cell (98 hours). All these results confirm that the DS57-K membrane efficiently retards the crossover of redox species owing to the SPEEK-K frameworks and the optimized DS.

3.2. CuS-CF Electrode for PFRFBs. SEM images reveal the significant differences between pristine CF (Figures 5(a) and 5(b)) and CuS-CF (Figures 5(c) and 5(d)) on the morphologies, indicating the successful growth of $\mathrm{CuS}$ on the surfaces of the CF. In specific, the surfaces of pristine $\mathrm{CF}$ are clean and smooth, while CuS-CF presents a flower-like bump structure, and these bumps are composed of numerous interconnected nanosheets. This flower-like structure can provide more active sites for redox reactions to occur. Figure S5 shows the EDS mapping results of the CuS-CF, which confirms the homogeneous distribution of $\mathrm{S}$ and $\mathrm{Cu}$ elements on CF.

As shown in Figure 6(a), multiple pairs of redox peaks can be observed on CuS-CF, while only one major pair of redox peaks can be clearly identified on the pristine CF electrode. The emergence of multiple polysulfide redox peaks indicates the excellent catalytic performance of the CuS-CF electrode. As illustrated in Figure 6(b), the EIS tests have been employed to understand the electrochemical properties of pristine $\mathrm{CF}$ and $\mathrm{CuS}-\mathrm{CF}$. The charge transfer resistance of
CuS-CF is $2.14 \Omega$, which is lower than that of pristine CF $(3.34 \Omega)$. This result suggests that the CuS-CF electrode exhibits a faster electron transfer speed between the electrode interface and the electrolyte. When the scanning rate varied from 1 to $50 \mathrm{mV} \mathrm{s}^{-1}$, the main redox peaks display higher current densities and smaller separation of peak potentials at all scan rates on CuS-CF than those on pristine CF (Figures S6a and S6b). These results indicate that the surface coverage of flower-like $\mathrm{CuS}$ offers more active sites for polysulfide redox reactions and leads to higher electrochemical activities. Similar phenomena have also been observed in earlier reports $[52,53]$.

To evaluate the influences of electrodes on the cell performance, PFRFB cells have been assembled using pristine $\mathrm{CF}$ and $\mathrm{CuS}-\mathrm{CF}$ as electrodes, respectively. As disclosed by the charge/discharge curves (Figure 6(c)), the CuS-CFbased cell exhibits a smaller polarization in the first cycle compared with the pristine CF-based cell. Such difference is further enlarged during the cycling process. The pristine CF-based cell shows evident IR drop, which is negligible when $\mathrm{CuS}-\mathrm{CF}$ electrode is utilized. Correspondingly, the CuS-CF electrode enables more stable EE of the PFRFB cell over cycling, which remains at $75.80 \%$ after 879 cycles, compared to that of $66.54 \%$ after 751 cycles when CF electrode is used (Figure 6(d)). These significant improvements of cell 


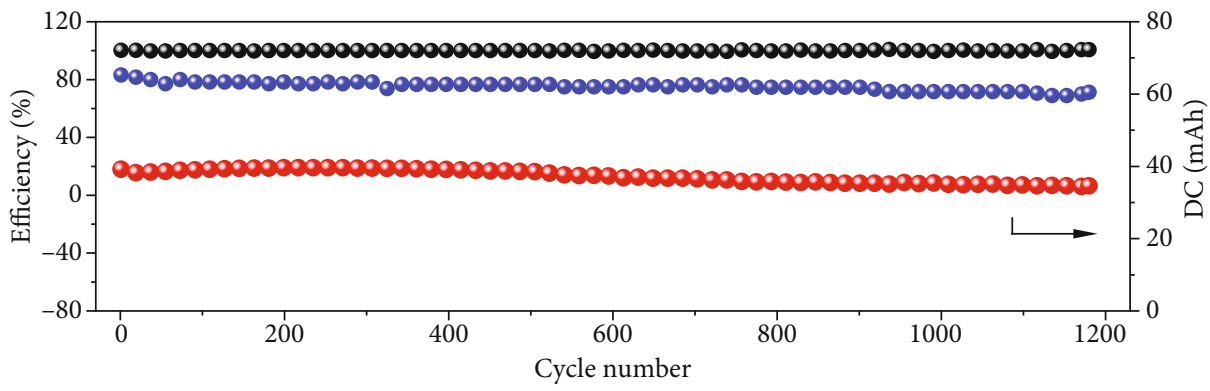

- $\mathrm{CE}$

- EE

- DC DS57-K/CuS-CF

(a)

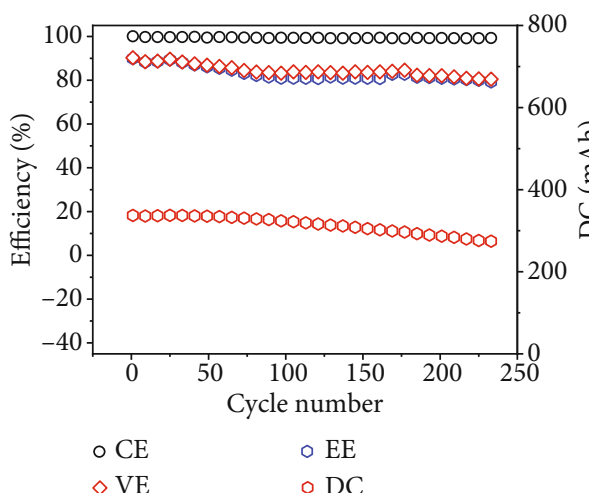

(b)

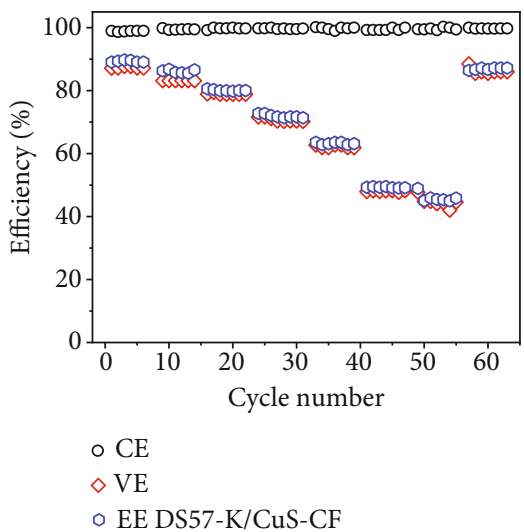

(d)

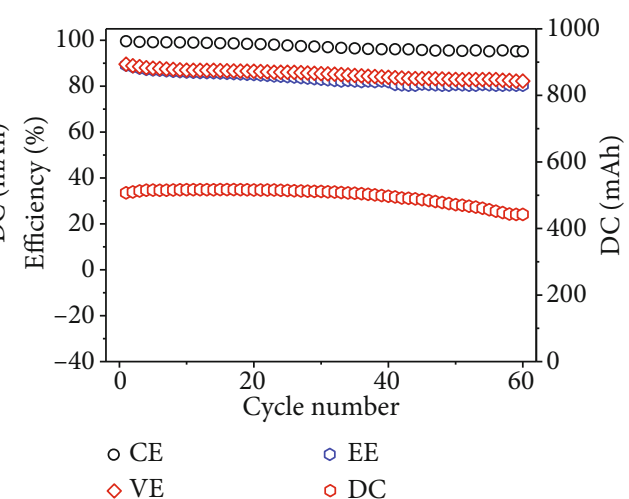

(c)

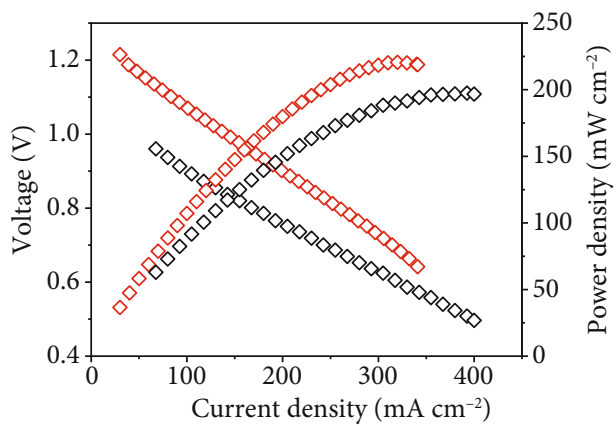

$\diamond \mathrm{N} 212-\mathrm{K} / \mathrm{CF}$

$\diamond \mathrm{DS} 57-\mathrm{K} / \mathrm{CuS}-\mathrm{CF}$

(e)

Figure 7: (a) CE, EE, and DC of a PFRFB cell comprised of a $15.0 \mathrm{~mL}$ solution of $0.1 \mathrm{M} \mathrm{K}_{3}\left[\mathrm{Fe}(\mathrm{CN})_{6}\right]+2.0 \mathrm{M} \mathrm{KCl}$ as the catholyte at a current density of $50 \mathrm{~mA} \mathrm{~cm}^{-2}$. (b) Electrochemical performance of a PFRFB cell with a $25.0 \mathrm{~mL}$ solution of $0.5 \mathrm{M} \mathrm{K} \mathrm{K}_{3}\left[\mathrm{Fe}(\mathrm{CN})_{6}\right]+2.0 \mathrm{M} \mathrm{KCl}$ as the catholyte at a current density of $20 \mathrm{~mA} \mathrm{~cm}^{-2}$. (c) Electrochemical performance of a PFRFB cell with a $25.0 \mathrm{~mL}$ solution of $0.8 \mathrm{M}$ $\mathrm{K}_{3}\left[\mathrm{Fe}(\mathrm{CN})_{6}\right]+2.0 \mathrm{M} \mathrm{KCl}$ as the catholyte at a current density of $20 \mathrm{~mA} \mathrm{~cm}^{-2}$. (d) Rate performance from $20 \mathrm{~mA} \mathrm{~cm}^{-2}$ to $140 \mathrm{~mA} \mathrm{~cm}^{-2}$ of a PFRFB cell with $0.5 \mathrm{M} \mathrm{K}_{3}\left[\mathrm{Fe}(\mathrm{CN})_{6}\right]+2.0 \mathrm{M} \mathrm{KCl}$ as the catholyte. (e) The polarization curves of PFRFB cells employing different electrode and ion-exchange membrane with $0.8 \mathrm{M} \mathrm{K}_{3}\left[\mathrm{Fe}(\mathrm{CN})_{6}\right]+2.0 \mathrm{M} \mathrm{KCl}$ as the catholyte at $100 \%$ SOC. Note that from (a) to (e), $15.0 \mathrm{~mL}$ solutions of $2.0 \mathrm{M} \mathrm{K}_{2} \mathrm{~S}+1.0 \mathrm{M} \mathrm{KCl}$ were used as anolytes for all the cells.

performance that originated from electrodes can be explained by the more catalytic sites and active sites in CuS-CF [52].

3.3. Comprehensive PFRFB Performance. To explore the synergistic effects of the two key materials, CuS-CF is used as the anodic electrode in combination with the optimum
DS57-K as the ion-exchange membrane in one PFRFB cell. As shown in Figure 7(a), at the beginning, the discharge capacity (DC) can achieve as high as $99.54 \%$ of the theoretical value. The $\mathrm{CE}$ keeps very stable over the long-term cycling test (99.95\% after 1180 cycles), and the average EE of the PFRFB is $75.41 \%$ even at a high current density of $50 \mathrm{~mA} \mathrm{~cm}^{-2}$. In this study, the capacity of the cell is 
determined by the catholyte. When the concentration of redox-active material $\left(\mathrm{K}_{3}\left[\mathrm{Fe}(\mathrm{CN})_{6}\right]\right)$ in the catholyte is increased to be $0.5 \mathrm{M}$ and $0.8 \mathrm{M}$, the DC values display apparent enhancements (Figures $7(\mathrm{~b})$ and $7(\mathrm{c})$ ). Besides, when $0.5 \mathrm{M} \mathrm{K}_{3}\left[\mathrm{Fe}(\mathrm{CN})_{6}\right]+2.0 \mathrm{M} \mathrm{KCl}$ is employed as the catholyte, the cell delivers outstanding performance at a current density of $20 \mathrm{~mA} \mathrm{~cm}^{-2}$, including the CE of $99.28 \%$, the VE of $80.46 \%$, and the $\mathrm{EE}$ of $79.27 \%$. These key parameters remain steady for more than 230 cycles (Figure $7(\mathrm{~b})$ ). When the catholyte contains $0.8 \mathrm{M} \mathrm{K} \quad \mathrm{K}_{3}\left[\mathrm{Fe}(\mathrm{CN})_{6}\right]+2.0 \mathrm{M} \mathrm{KCl}$ (Figure $7(\mathrm{c})$ ), the resulting cell exhibits minor capacity decay during 60 cycles (180 testing hours) at a current density of $20 \mathrm{~mA} \mathrm{~cm}^{-2}$, and the capacity decay rate is $0.0709 \%$ per hour. The average CE, EE, and VE of this more concentrated PFRFB cell achieve $97.21 \%, 83.41 \%$, and $85.23 \%$, respectively.

Rate performance of the PFRFB cell was collected from 20 to $140 \mathrm{~mA} \mathrm{~cm}^{-2}$ with an interval of $20 \mathrm{~mA} \mathrm{~cm}^{-2}$. The CE maintains at nearly $100 \%$ under all applied current densities, suggesting the high stability of both the DS57-K membrane and the CuS-CF electrode. The VE and the EE decrease strikingly with the increment of current density from $100 \mathrm{~mA} \mathrm{~cm}^{-2}$ to $140 \mathrm{~mA} \mathrm{~cm}^{-2}$, which may be related to the increase of electrochemical polarization and ohmic polarization of the cell. Despite that, when the current density returns to $20 \mathrm{~mA} \mathrm{~cm}^{-}$ ${ }^{2}$, both the $\mathrm{VE}$ and the $\mathrm{EE}$ regain the initial high values. In addition, the polarization curves confirm that the power density of the cell becomes higher along with the concentration of redox-active materials in the catholyte increasing (Figure S7). For comparison, a PFRFB cell with pristine $\mathrm{CF}$ as electrodes and $\mathrm{N} 212-\mathrm{K}$ as the ion-exchange membrane (the reference cell) was assembled and tested. From the polarization curves, the peak power density of the cell with optimized electrodes and membrane reaches $223 \mathrm{~mW} \mathrm{~cm}^{-2}$, which is higher than $199 \mathrm{~mW} \mathrm{~cm}^{-2}$ of the reference cell (Figure 7(e)). Therefore, by the optimizations of membrane and electrode materials, the cost of the PFRFB system is reduced and the redox reaction kinetics of polysulfide species is improved.

\section{Conclusions}

In summary, we report a neutral PFRFB system by using an affordable SPEEK-K membrane and a highly catalytic CuS$\mathrm{CF}$ electrode. By the optimization of DS, the DS57-K membrane enables the PFRFB cell high average CE of $99.80 \%$ and superior EE of $90.42 \%$ over 1051 cycles at a current density of $20 \mathrm{~mA} \mathrm{~cm}^{-2}$, surpassing the commercial N212 membrane in terms of both performance and affordability. Meanwhile, to match with the fast kinetics of the catholyte redox reactions, CuS-CF electrode is demonstrated with excellent catalytic effects on the polysulfide redox reactions, leading to the reduced polarization of the cell over long-term cycling. By combining the DS57-K membrane with the CuS-CF electrode, the PFRFB cell exhibits high efficiencies even at a high current density of $50 \mathrm{~mA} \mathrm{~cm}^{-2}$. Furthermore, with such strategy, a high concentrated catholyte with $0.8 \mathrm{M} \mathrm{K}_{3}\left[\mathrm{Fe}(\mathrm{CN})_{6}\right]$ is employed in the proposed PFRFB cell, leading to an outstanding power density of $223 \mathrm{~mW} \mathrm{~cm}^{-2}$. Therefore, advances achieved in this study promote the development of neutral PFRFBs for highperformance and low-cost energy storage systems.

\section{Data Availability}

The authors declare that the main data supporting the findings in this study are available within the article and its supplementary information. Additional data are available from the corresponding authors upon reasonable request.

\section{Conflicts of Interest}

The authors declare that there is no conflict of interest regarding the publication of this article.

\section{Authors' Contributions}

M.D., X.Z., and C.J. proposed the project, designed the experiment, and revised the manuscript. X.L. performed the most experiments and prepared the initial draft. H.F., J.X., and Y.L. characterized the electrodes, analyzed the data, and prepared the figures. S.Y. and H.Z. prepared and characterized the membranes. B.L. and M.H. performed optical measurements.

\section{Acknowledgments}

We acknowledge financial support from the 100 Talented Team of Hunan Province (XiangZu [2016] 91), the "Huxiang High-Level Talents" program (2019RS1046 and 2018RS3077), the Open Fund of National Engineering Laboratory of Highway Maintenance Technology (Changsha University of Science and Technology) (kfj170105), the Natural Science Foundation of Hunan Province (2020JJ5566), and the Outstanding Young Talent Project of Education Department of Hunan Province (19B029).

\section{Supplementary Materials}

Figure S1: a diffusion cell for permeability measurements. Figure S2: characterizations of the N212 membrane. Figure S3: comparisons of cell performance with different membranes. Figure S4: self-discharge behaviors of the PFRFB cells with different membranes. Figure S5: the SEM and EDS mapping images of CuS-CF. Figure S6: the CV curves on pristine $\mathrm{CF}$ and $\mathrm{CuS}-\mathrm{CF}$ electrode at different scanning rates, respectively. Figure S7: the polarization curves of cells with different concentrations of $\mathrm{K}_{3}\left[\mathrm{Fe}(\mathrm{CN})_{6}\right]$ in the catholyte. Methods S1: cost calculations. Table S1: cost of membranes. (Supplementary Materials)

\section{References}

[1] H. M. Zhang, W. J. Lu, and X. F. Li, "Progress and perspectives of flow battery technologies," Electrochemical Energy Reviews, vol. 2, no. 3, pp. 492-506, 2019.

[2] Z. G. Yang, J. L. Zhang, M. C. W. Kintner-Meyer et al., "Electrochemical energy storage for green grid," Chemical Reviews, vol. 111, no. 5, pp. 3577-3613, 2011.

[3] C. K. Zhang, L. Y. Zhang, Y. Ding et al., "Progress and prospects of next-generation redox flow batteries," Energy Storage Materials, vol. 15, pp. 324-350, 2018. 
[4] J. Y. Ye, D. Yuan, M. Ding et al., “A cost-effective nafion/lignin composite membrane with low vanadium ion permeation for high performance vanadium redox flow battery," Journal of Power Sources, vol. 482, no. 15, pp. 229023-229030, 2021.

[5] J. Luo, B. Hu, M. W. Hu, Y. Zhao, and T. L. Liu, "Status and prospects of organic redox flow batteries toward sustainable energy storage," ACS Energy Letters, vol. 4, no. 9, pp. 22202240, 2019.

[6] Y. Long, M. Ding, and C. K. Jia, "Application of nanomaterials in aqueous redox flow batteries," Chem NanoMat, vol. 7, no. 7, pp. 699-712, 2021.

[7] M. Skyllas-Kazacos, G. Kazacos, G. Poon, and H. Verseema, "Recent advances with UNSW vanadium-based redox flow batteries," International Journal of Energy Research, vol. 34, no. 2, pp. 182-189, 2010.

[8] L. Xia, T. Long, W. Y. Li et al., "Highly stable vanadium redoxflow battery assisted by redox-mediated catalysis," Small, vol. 16, no. 38, pp. 2003321-2003330, 2020.

[9] T. Long, Y. Long, M. Ding et al., "Large scale preparation of 20 $\mathrm{cm} \times 20 \mathrm{~cm}$ graphene modified carbon felt for high performance vanadium redox flow battery," Nano Research, vol. 14, no. 10, pp. 3538-3544, 2021.

[10] C. X. Wang, X. Li, B. Yu et al., "Molecular design of fused-ring phenazine derivatives for long-cycling alkaline redox flow batteries," ACS Energy Letters, vol. 5, no. 2, pp. 411-417, 2020.

[11] W. Yan, C. X. Wang, J. Q. Tian et al., "All-polymer particulate slurry batteries," Nature Communications, vol. 10, pp. 25132523, 2019.

[12] M. G. Pan, Y. Lu, S. Y. Lu et al., "The dual role of bridging phenylene in an extended bipyridine system for high-voltage and stable two-electron storage in redox flow batteries," ACS Applied Materials \& Interfaces, vol. 13, no. 37, pp. 4417444183, 2021.

[13] S. L. Chang, J. Y. Ye, W. Zhou et al., "A low-cost SPEEK-K type membrane for neutral aqueous zinc-iron redox flow battery," Surface \& Coatings Technology, vol. 358, no. 25, pp. 190-194, 2019.

[14] J. Luo, W. D. Wu, C. Debruler, B. Hu, M. W. Hu, and T. L. Liu, "A $1.51 \mathrm{~V} \mathrm{pH}$ neutral redox flow battery towards scalable energy storage," Journal of Materials Chemistry A, vol. 7, pp. 9130-9136, 2019.

[15] T. Janoschka, N. Martin, U. Martin et al., "An aqueous, polymer-based redox-flow battery using non-corrosive, safe, and low-cost materials," Nature, vol. 527, pp. 78-81, 2015.

[16] X. L. Wei, W. Xu, M. Vijayakumar et al., “TEMPO-based catholyte for high-energy density nonaqueous redox flow batteries," Advanced Materials, vol. 26, no. 45, pp. 7649-7653, 2014.

[17] B. H. Robb, J. M. Farrell, and M. P. Marshak, "Chelated chromium electrolyte enabling high-voltage aqueous flow batteries," Joule, vol. 3, no. 10, pp. 2503-2512, 2019.

[18] C. X. Xie, Y. Q. Duan, W. B. Xu, H. M. Zhang, and X. F. Li, “A low-cost neutral zinc-iron flow battery with high energy density for stationary energy storage," Angewandte Chemie International Edition, vol. 56, no. 47, pp. 14953-14957, 2017.

[19] C. X. Wang, Z. Yang, Y. R. Wang et al., "High-performance alkaline organic redox flow batteries based on 2-hydroxy-3carboxy-1, 4-naphthoquinone," ACS Energy Letters, vol. 3, no. 10, pp. 2404-2409, 2018.

[20] B. Li, Z. M. Nie, M. Vijayakumar et al., "Ambipolar zincpolyiodide electrolyte for a high-energy density aqueous redox flow battery," Nature Communications, vol. 6, pp. 6303163038, 2015.

[21] E. S. Beh, D. D. Porcellinis, R. L. Gracia, K. T. Xia, R. G. Gordon, and M. J. Aziz, "A neutral $\mathrm{pH}$ aqueous organicorganometallic redox flow battery with extremely high capacity retention," ACS Energy Letters, vol. 2, no. 3, pp. 639-644, 2017.

[22] B. Hu, J. Luo, M. W. Hu, B. Yuan, and T. L. Liu, “A pH-neutral, metal-free aqueous organic redox flow battery employing an ammonium anthraquinone anolyte," Angewandte Chemie International Edition, vol. 58, no. 46, pp. 16629-16636, 2019.

[23] C. X. Wang, B. Yu, Y. Z. Liu et al., "N-Alkyl-carboxylate-functionalized anthraquinone for long-cycling aqueous redox flow batteries," Energy Storage Materials, vol. 36, pp. 417-426, 2021.

[24] F. R. Brushett, M. J. Aziz, and K. E. Rodby, "On lifetime and cost of redox-active organics for aqueous flow batteries," ACS Energy Letters, vol. 5, no. 3, pp. 879-884, 2020.

[25] M. H. Yang, Z. Z. Xu, W. Z. Xiang et al., "High performance and long cycle life neutral zinc-iron flow batteries enabled by zinc-bromide complexation," Energy Storage Materials, vol. 44, pp. 433-440, 2022.

[26] G. Cong, W. Wang, N. C. Lai, Z. Liang, and Y. C. Lu, "A highrate and long-life organic-oxygen battery," Nature Materials, vol. 18, no. 4, pp. 390-396, 2019.

[27] Y. Ding, C. K. Zhang, L. Y. Zhang, Y. G. Zhou, and G. H. Yu, "Molecular engineering of organic electroactive materials for redox flow batteries," Chemical Society Reviews, vol. 47, pp. 69-103, 2018.

[28] G. D. Li, W. Chen, H. Zhang et al., "Membrane-free $\mathrm{Zn} / \mathrm{MnO}_{2}$ flow battery for large-scale energy storage," Advanced Energy Materials, vol. 10, no. 9, pp. 1902085-1902094, 2020.

[29] Z. Li, M. S. Pan, L. Su et al., "Air-breathing aqueous sulfur flow battery for ultralow-cost long-duration electrical storage," Joule, vol. 1, no. 2, pp. 306-327, 2017.

[30] X. L. Wei, G.-G. Xia, B. Kirby et al., “An aqueous redox flow battery based on neutral alkali metal ferri/ferrocyanide and polysulfide electrolytes," Journal of the Electrochemical Society, vol. 163, no. 1, pp. A5150-A5153, 2016.

[31] D. G. Kwabi, K. X. Lin, Y. L. Ji et al., "Alkaline quinone flow battery with long lifetime at $\mathrm{pH}$ 12," Joule, vol. 2, no. 9, pp. 1894-1906, 2018.

[32] D. G. Kwabi, Y. L. Ji, and M. J. Aziz, "Electrolyte lifetime in aqueous organic redox flow batteries: a critical review," Chemical Reviews, vol. 120, no. 14, pp. 6467-6489, 2020.

[33] J. Hong, M. Lee, B. Lee, D. H. Seo, C. B. Park, and K. Kang, "Biologically inspired pteridine redox centres for rechargeable batteries," Nature Communications, vol. 5, pp. 5335-5343, 2014.

[34] Z. Yang, L. Tong, D. P. Tabor et al., "Alkaline benzoquinone aqueous flow battery for large-scale storage of electrical energy," Advanced Energy Materials, vol. 8, no. 8, pp. 1702056-1702064, 2018.

[35] K. X. Lin, R. Gómez-Bombarelli, E. S. Beh et al., "A redox-flow battery with an alloxazine-based organic electrolyte," Nature Energy, vol. 1, pp. 16102-16109, 2016.

[36] S. Yun, S. H. Park, J. S. Yeon et al., "Materials and device constructions for aqueous lithium-sulfur batteries," Advanced Functional Materials, vol. 28, no. 38, pp. 1707593-1707609, 2018. 
[37] S. P. Li, X. Chen, F. Hu et al., "Cobalt-embedded carbon nanofiber as electrocatalyst for polysulfide redox reaction in lithium sulfur batteries," Electrochimica Acta, vol. 304, no. 1, pp. 11-19, 2019.

[38] Y. Jin, G. M. Zhou, F. F. Shi et al., "Reactivation of dead sulfide species in lithium polysulfide flow battery for grid scale energy storage," Nature Communications, vol. 8, pp. 462-470, 2017.

[39] M. M. Gross and A. Manthiram, "Rechargeable zinc-aqueous polysulfide battery with a mediator-ion solid electrolyte," ACS Applied Materials \& Interfaces, vol. 10, no. 13, pp. 10612-10617, 2018.

[40] B. K. Cao, J. T. Huang, Y. Mo, C. Y. Xu, Y. Chen, and H. T. Fang, "A collaboratively polar conductive interface for accelerating polysulfide redox conversion," ACS Applied Materials \& Interfaces, vol. 11, no. 15, pp. 14035-14043, 2019.

[41] L. Su, A. F. Badel, C. S. Cao, J. J. Hinricher, and F. R. Brushett, "Toward an inexpensive aqueous polysulfide-polyiodide redox flow battery," Industrial \& Engineering Chemistry Research, vol. 56, no. 35, pp. 9783-9792, 2017.

[42] Y. Long, Z. Z. Xu, G. X. Wang et al., “A neutral polysulfide/ferricyanide redox flow battery," iScience, vol. 24, pp. 103157103169, 2021.

[43] Z. Li, G. Weng, Q. Zou, G. Cong, and Y. C. Lu, "A high-energy and low-cost polysulfide/iodide redox flow battery," Nano Energy, vol. 30, pp. 283-292, 2016.

[44] C. K. Jia, Y. H. Cheng, X. Ling, G. J. Wei, J. G. Liu, and C. W. Yan, "Sulfonated poly (ether ether ketone)/functionalized carbon nanotube composite membrane for vanadium redox flow battery applications," Electrochimica Acta, vol. 153, no. 20, pp. 44-48, 2015.

[45] J. Y. Ye, X. C. Lou, C. Wu et al., "Ion selectivity and stability enhancement of SPEEK/lignin membrane for vanadium redox flow battery: the degree of sulfonation effect," Frontiers in Chemistry, vol. 6, pp. 549-557, 2018.

[46] X. C. Lou, B. Lu, M. R. He et al., "Functionalized carbon black modified sulfonated polyether ether ketone membrane for highly stable vanadium redox flow battery," Journal of Membrane Science, vol. 643, no. 1, pp. 120015-120022, 2022.

[47] D. Ma, B. Hu, W. D. Wu et al., "Highly active nanostructured $\mathrm{CoS}_{2} / \mathrm{CoS}$ heterojunction electrocatalysts for aqueous polysulfide/iodide redox flow batteries," Nature Communications, vol. 10, pp. 3367-3374, 2019.

[48] Z. Li and Y. C. Lu, "Polysulfide-based redox flow batteries with long life and low levelized cost enabled by charge-reinforced ion-selective membranes," Nature Energy, vol. 6, pp. 517528, 2021.

[49] E. J. Radich, R. Dwyer, and P. V. Kamat, " $\mathrm{Cu}_{2} \mathrm{~S}$ reduced graphene oxide composite for high-efficiency quantum dot solar cells. Overcoming the redox limitations of $\mathrm{S}_{2}{ }^{-} / \mathrm{S}_{\mathrm{n}}{ }^{2-}$ at the counter electrode," The Journal of Physical Chemistry Letters, vol. 2, no. 19, pp. 2453-2460, 2011.

[50] M. Ding, X. Ling, D. Yuan et al., "SPEEK membrane of ultrahigh stability enhanced by functionalized carbon nanotubes for vanadium redox flow battery," Frontiers in Chemistry, vol. 6, pp. 286-294, 2018.

[51] C. K. Jia, J. G. Liu, and C. W. Yan, "A significantly improved membrane for vanadium redox flow battery," Journal of Power Sources, vol. 195, no. 13, pp. 4380-4383, 2010.
[52] M. Q. Gao, S. P. Huang, F. F. Zhang, Y. M. Lee, S. Q. Huang, and Q. Wang, "Successive ionic layer adsorption and reaction-deposited copper sulfide electrocatalyst for highpower polysulfide-based aqueous flow batteries," Materials Today Energy, vol. 18, pp. 100540-100547, 2020.

[53] J. Xu, W. X. Zhang, H. B. Fan, F. L. Cheng, D. W. Su, and G. X. Wang, "Promoting lithium polysulfide/sulfide redox kinetics by the catalyzing of zinc sulfide for high performance lithium-sulfur battery," Nano Energy, vol. 51, pp. 73-82, 2018. 